\title{
FORMULATION DEVELOPMENT OF ORAL FAST-DISSOLVING FILMS OF RUPATADINE FUMARATE
}

\author{
ABHIBRATA ROY, REEGAN AREES, MADHAVI BLR \\ Department of Pharmaceutics, Acharya and BM Reddy College of Pharmacy, Bengaluru, Karnataka, India. Email: madhaviblr@gmail.com
} Received: 22 July 2020, Revised and Accepted: 24 August 2020

ABSTRACT

Objective: Rupatadine fumarate (RF) is an anti-allergic drug indicated for the treatment of allergic rhinitis. It has low oral bioavailability due to its poor aqueous solubility and extensive hepatic first pass metabolism. In the present work, oral fast-dissolving films (OFDF) have been formulated and evaluated to facilitate dissolution in the oral cavity.

Methods: Pullulan and HPMC (5, 15 cps) were employed as film formers and six formulations were tried. The physicochemical compatibility between drug and the polymers was studied by Fourier Transform Infrared ( FTIR) spectroscopy. RF-beta-cyclodextrin (BCD) inclusion complex was initially prepared and evaluated. The inclusion complex was incorporated into the film. OFDF were formulated and prepared by solvent casting method. The film size for one dose was $2 \times 2 \mathrm{~cm}$. The films were evaluated for various film parameters including disintegration time and drug release.

Results: Preliminary film studies indicated \% of film former solution to be between 3\% and $5 \%$ for good appearance, mechanical strength, and quick disintegration. Solubility enhancement of RF is almost 40-fold from its BCD inclusion complex. Drug content in the films ranged between $83 \%$ and $90 \%$. The pH ranged between 6 and 7 for all the formulations. All OFDF of RF disintegrated within one minute. With higher viscosity grade of HPMC, disintegration was comparatively slower and so was the drug release. Pullulan based films also showed desirable properties. F3 had disintegration time of $28 \mathrm{~s}$ and $\%$ drug release was $92 \%$ in $180 \mathrm{~s}$.

Conclusion: OFDF of RF could be formulated employing pullulan and HPMC low viscosity grades by solvent casting method. F3 containing HPMC E5 at $37 \%$ by weight of dry film showed desirable film properties. Stability studies indicated that there was no significant change in the films with respect to physicochemical properties and in vitro release.

Keywords: Rupatadine Fumarate, Oral Fast Dissolving Film, Solvent casting method, Beta Cyclodextrin, HPMC, Pullulan, Allergic Rhinitis.

(C) 2020 The Authors. Published by Innovare Academic Sciences Pvt Ltd. This is an open access article under the CC BY license (http://creativecommons. org/licenses/by/4. 0/) DOI: http://dx.doi.org/10.22159/ajpcr.2020.v13i11.39185

\section{INTRODUCTION}

Rhinitis, a common condition that affects up to $40 \%$ of the population, is the inflammation of the nasal mucosa. Allergic rhinitis occurs due to exposure to an inciting allergen such as airborne dustmite fecal particles, cockroach residues, animal dander, molds, and pollens. The inflammatory mediators and cytokines are released over the next 4-8 $\mathrm{h}$ in response to the allergen [1]. Allergic rhinitis is classified as intermittent when the total duration of the episode of inflammation is $<6$ weeks and persistent when symptoms continue throughout the year [2]. Treatment options for allergic rhinitis consist of allergen avoidance, pharmacotherapy, immunotherapy, and surgery [3]. Rupatadine fumarate (RF) is a selective non-sedating and long-acting oral histamine indicated for use in seasonal allergic rhinitis (SAR) or perennial allergic rhinitis (PAR) and chronic idiopathic urticaria. The dose is $10-40 \mathrm{mg}$. It has low oral bioavailability (50\%) due to low solubility and extensive hepatic first-pass metabolism [4].

Oral films are a group of flat thin films which are administered into the oral cavity. They rapidly release the active agent for local and/or systemic action. This film can incorporate soluble, insoluble or taste masked drug substances [5]. Oral fast-dissolving films (OFDF) offer fast, accurate dosing in a safe, efficacious format that is convenient and portable and can be administered without water or any special devices [6]. They are made from aqueous polymer matrices to achieve certain physical properties. OFDF are promising drug delivery systems for various indications such as allergy, pain, and migraine which require immediate attention [7]. The OFDF are suitable systems for drug categories such as antiepileptic[8], anti-inflammatory [9], antihistaminic [10], and antiemetics [11] to name a few.
Much of the research work on RF is related to the analytical method development. Formulation research includes preparation of its immediate release tablets by $\mathrm{QbD}$ approach[12] and as a model drug for taste masking by employing ethyl cellulose [13]. Patents on liquid oral formulations of the drug have been published [14]. No work has been tried on oral fast dissolving systems of RF. The purpose of the present study is to formulate and evaluate RF OFDF by solvent casting method for allergic rhinitis.

\section{METHODOLOGY}

\section{Materials}

RF was a generous gift sample from Hetero Labs, Hyderabad, India. Hydroxy propyl methyl cellulose (HPMC) 5 cps and $15 \mathrm{cps}$, Pullulan, Aspartame, and Beta-cyclodextrin were procured from Yarrow Chem Products, Mumbai. Sodium Starch Glycolate obtained from SD Fine Chemicals. Polyethylene glycol 400 and Tween 80 were obtained from Karnataka Fine Chemicals, India. All other chemicals and reagents used were of pharmacopeial grade and procured from other commercial sources.

\section{Methods}

Preformulation studies were carried out to identify the drug, to check the compatibility between drug and various polymers and develop analytical method for the drug.

\section{Melting point determination}

Melting point of RF was determined using Thiele's Tube method.

\section{Drug-excipient compatibility study}

Physical mixtures of RF and excipients were prepared and subjected to evaluation by infrared spectroscopy (IR) employing the Tensor 27, 
Bruker Optics IR Spectrophotometer. The spectra of physical mixtures were compared to those of pure drug and polymers.

\section{Determination of $\lambda_{\text {max }}$ and construction of standard plot of $R F$}

About $50 \mathrm{mg}$ of drug was weighed and dissolved in $1 \mathrm{ml}$ methanol which is used as a cosolvent and made up to $50 \mathrm{ml}$ with phosphate buffer $\mathrm{pH}$ 6.8. Suitable dilutions were scanned in Agilent Technology Cary 60 UVVisible spectrophotometer between $200 \mathrm{~nm}$ and $400 \mathrm{~nm}$. Stock solution of RF of strength $1000 \mu \mathrm{g} / \mathrm{ml}$ was made in phosphate buffer $\mathrm{pH} 6.8$ with methanol as cosolvent. From this solution, a series of dilutions were made with buffer to obtain $10,20,30,40$, and $50 \mu \mathrm{g} / \mathrm{ml}$ solutions. The absorbance was measured against blank phosphate buffer $\mathrm{pH} 6.8$ solution at the obtained $\lambda_{\max }(238 \mathrm{~nm})$.

\section{Preliminary film formation study}

Three polymers, that is, Pullulan, HPMC E5 and HPMC E15 were individually tried at levels of $3 \%, 4 \%$, and $5 \% \mathrm{w} / \mathrm{w}$. All the trial batches contained PEG 400 as plasticizer at three levels of $10 \% 15 \%$, and $20 \%$.w/w. Based on the appearance of the film, folding endurance and disintegration optimal plasticizer was chosen.

\section{Preparation of RF-beta cyclodextrin complex}

Inclusion complex of RF was prepared by kneading method. Equimolar concentrations of RF and BCD (1:1) were added to a mortar and mixed by trituration. Methanol and distilled water were added in small volumes to obtain slurry. The slurry was kneaded for $45 \mathrm{~min}$ and then dried on a Petri plate in a hot air oven at $45^{\circ} \mathrm{C}$. The dried complex was scraped, crushed, and passed through $80 \#$ sieve. The fine powder was collected for further evaluation and processing

\section{Evaluation of RF-beta-cyclodextrin complex}

The drug-inclusion complex was evaluated for drug content, solubility, and dissolution.

\section{Drug content}

RF-BCD complex, $25 \mathrm{mg}$, was taken into a $25 \mathrm{ml}$ volumetric flask. The contents were dissolved and the volume was made up to the mark with phosphate buffer $\mathrm{pH}$ 6.8. The solution was suitably diluted and absorbance was measured UV spectrophotometrically at $238 \mathrm{~nm}$. Drug content was then calculated.

\section{Saturation solubility study}

Solubility study was carried out by shake flask method to determine the effect of inclusion complexation on solubility enhancement for RF. Known excess of RF-BCD complex was added to $10 \mathrm{ml}$ distilled water taken in glass vials. The samples were shaken for $24 \mathrm{~h}$ at room temperature in a rotary shaker. After $24 \mathrm{~h}$, the vials were allowed to equilibrate. The solution was filtered, suitably diluted, and analyzed spectrophotometrically at $238 \mathrm{~nm}$ for the dissolved drug.

\section{Dissolution study of RF-beta cyclodextrin complex}

Dissolution studies were carried out for RF-BCD complex, taken as powder equivalent to $100 \mathrm{mg}$ RF. The study was conducted employing USP dissolution apparatus Type 1 containing $900 \mathrm{ml}$ phosphatebuffered pH 6.8 maintained at $37 \pm 0.5^{\circ} \mathrm{C}$ stirred at $50 \mathrm{rpm}$. The samples were periodically withdrawn at suitable time intervals $5,10,15,20$, 30,45 , and 60 min and volume replaced with the equivalent volume of buffer. The samples were filtered and diluted. The absorbance of the resulting solutions was measured at $238 \mathrm{~nm}$ using UV-visible spectrophotometer [15].

\section{Formulation and preparation of RF OFDF}

OFDF containing RF were prepared by solvent casting technique. The formulation details are provided in Table 1. Polymers employed were HPMC and Pullulan. Aqueous polymeric solution was prepared by employing a magnetic stirrer. Separately, calculated amount of
RF-BCD complex was dissolved in the distilled water, followed by addition of required amount of PEG 400 (plasticizer), aspartame (sweetener), Tween 80 (wetting agent), and sodium starch glycolate (superdisintegrant). The contents were stirred to form a homogenous solution. Drug and polymer solutions were mixed and then cast on a Petri plate. The area of the Petri plate in which the films were casted was of $73.28 \mathrm{~cm}^{2}$. The solution was allowed to dry in a hot air oven at $40^{\circ} \mathrm{C}$ for $24 \mathrm{~h}$. The film formed was carefully removed from the plate and cut into square strips of side $2 \mathrm{~cm}$ each, designed to contain $10 \mathrm{mg}$ of RF

\section{Evaluation of RF OFDF}

Uniformity of weight

Square OFDF strips of size $2 \times 2 \mathrm{~cm}$, were taken and the individual weights, were determined employing a digital balance. The average weight was calculated $(n=3)$.

\section{Folding endurance}

Folding endurance was determined by folding the film at the same place repeatedly till it broke. The number of folds which the film could withstand before it breaking indicates folding endurance [16]

\section{Uniformity of film thickness}

Thickness of film was measured using screw gauge. Measurements were recorded from the center and the edges of the film.

\section{Percentage moisture absorption of the film}

OFDF strip of size $2 \times 2 \mathrm{~cm}$ was weighed and kept in a desiccator for $72 \mathrm{~h}(\mathrm{n}=3)$. The films were taken out after 3 days and kept in stability chamber at $75 \pm 5 \%$ relative humidity (RH) and $40 \pm 2^{\circ} \mathrm{C}$ for 1 day [17]. The calculation is done as per the following equation

$\%$ Moisture absorption $=\{($ Final weight - Initial weight $) /$ Final weight $\}$ $\times 100$ ).

Percentage moisture loss from the film

OFDF strip of size $2 \times 2 \mathrm{~cm}$ was initially weighed and kept in the desiccator $(n=3)$. After $72 \mathrm{~h}$, the film was taken out and reweighed [18]. The calculation is done as per the following equation

$\%$ Moisture loss $=\{($ Initial weight - final weight $) /$ Final weight $\} \times 100$.

Table 1: Formulation of RF-OFDF

\begin{tabular}{lllllll}
\hline Ingredients (mg) & \multicolumn{2}{l}{ Formulation } & & & \\
\cline { 2 - 7 } & F1 & F2 & F3 & F4 & F5 & F6 \\
\hline RF BCD complex & 624 & 624 & 624 & 624 & 624 & 624 \\
equivalent to 180 mg RF & & & & & & \\
Pullulan & 300 & 400 & - & - & - & - \\
HPMC E 5 cps & - & - & 400 & 500 & - & - \\
HPMC E 15 cps & - & - & - & - & 400 & 500 \\
Aspartame mg & 40 & 40 & 40 & 40 & 40 & 40 \\
PEG 400 ml & 2.0 & 2.0 & 2.0 & 2.0 & 2.0 & 2.0 \\
Tween 80 ml & 0.2 & 0.2 & 0.2 & 0.2 & 0.2 & 0.2 \\
Sodium starch glycolate & 20 & 20 & 20 & 20 & 20 & 20 \\
Distilled water to 10 ml & qs & qs & Qs & qs & qs & qs \\
\hline
\end{tabular}

Table 2: FTIR spectral details of RF and its mixtures

\begin{tabular}{llll}
\hline Vibrations & $\begin{array}{l}\text { RF } \\
\left(\mathbf{c m}^{-\mathbf{1}}\right)\end{array}$ & $\begin{array}{l}\text { RF }- \text { Pullulan } \\
\mathbf{( \mathbf { c m } ^ { - 1 } \mathbf { ) }}\end{array}$ & $\begin{array}{l}\text { RF-HPMC } \\
\mathbf{( \mathbf { c m } ^ { - 1 } \mathbf { ) }}\end{array}$ \\
\hline C=C (stretching) & 3000 & 3088 & 3020 \\
C=N (bending) & 1435 & 1421 & 1446 \\
C-H (stretching) & 2832 & 2897 & 2831 \\
C-Cl (bending) & 851 & 846 & 827 \\
O-H (stretching) & 3493 & 3552 & 3512 \\
\hline
\end{tabular}


Surface $p H$ study

Films were slightly moistened with water and the electrode of the digital pH meter was brought in contact with the surface of the films. The $\mathrm{pH}$ reading was noted [19].

\section{Drug content uniformity}

OFDF strip of size $2 \times 2 \mathrm{~cm}$ was cut from different places from casted films. Each strip was placed in $100 \mathrm{ml}$ volumetric flask and dissolved in phosphate-buffered $\mathrm{pH}$ 6.8. Suitable dilutions were made and the absorbance was measured at $238 \mathrm{~nm}$.

\section{Disintegration time}

In vitro disintegration time was determined visually in a glass beaker. $25 \mathrm{ml}$ distilled water maintained at $37^{\circ} \mathrm{C}$ is taken in the beaker and the OFDF strip was added. The contents were stirred gently every $10 \mathrm{~s}$. The time taken for the film to disintegrate is noted $(n=3)$.

\section{Percentage elongation of the film}

The prepared film was pulled by means of a pulley system. Weights were gradually added to the pan to increase the pulling force until the film was broken. The elongation was determined by noting the distance travelled by pointer on the graph paper before break of film [20].

$\%$ Elongation $=\left(\mathrm{L}_{1}-\mathrm{L}_{0}\right) / \mathrm{L}_{0} \times 100 ;$ where $\mathrm{L}_{1}=$ final length, $\mathrm{L}_{0}=$ Initial length.

In vitro drug release study

The release of RF from films was determined employing diffusion tube method. The study is carried out employing $250 \mathrm{ml}$ phosphatebuffered pH 6.8 maintained at $37 \pm 0.5^{\circ} \mathrm{C}$ and stirred at $50 \mathrm{rpm}$. Film of size $2 \times 2$ equivalent to $10 \mathrm{mg}$ of $\mathrm{RF}$ was used and it was kept in contact of the dissolution media through a presoaked cellophane membrane in a diffusion tube. The dissolution media were continuously stirred using a magnetic stirrer. $5 \mathrm{ml}$ aliquot were withdrawn at time intervals of $15,30,60,90,120,150$, and 180 s with replenishment of the buffer and the absorbance was taken at $238 \mathrm{~nm}$ after suitable dilution [21].
Stability study of optimized film

The formulation which showed most satisfactory performance was subjected for stability studies. Films were packed in Alu alu pouch and kept in stability chamber (Thermolab Scientific Equipment Ltd) maintained at $40 \pm 2^{\circ} \mathrm{C}$ and $75 \pm 5 \%$ RH. The samples were analyzed for the drug content (\%), disintegration time, and in vitro dissolution studies [9].

\section{RESULTS AND DISCUSSION}

\section{Melting point}

Melting point of RF was found to be $199^{\circ} \mathrm{C}$. The observed value is in agreement with the reported value to be between 194 and $201^{\circ} \mathrm{C}$.

\section{Drug-polymer compatibility study}

From the FTIR spectral data given in Table 2 and Figs. 1 and 2 based on the characteristic peaks of the drug, there is no incompatibility between the RF and the polymers.

Determination of $\lambda_{\text {max }}$ and construction of standard graph of RF The $\lambda_{\text {max }}$ was found to be $238 \mathrm{~nm}$. Standard plot of RF was determined in phosphate-buffered $\mathrm{pH} 6.8$ at $238 \mathrm{~nm}$ with methanol as cosolvent. The data are given in Table 3 . The regression equation generated was $y=0.0163 x . R^{2}$ value of 0.9985 indicates that the plot is linear and obeys Beer-Lambert's law in the concentration range of $0-50 \mu \mathrm{g} / \mathrm{ml}$. Low standard deviation values indicate precision. This plot is used for the estimation of drug in this work.

\section{Selection of polymers and plasticizers}

Three polymers, that is, pullulan, HPMC E5 and HPMC E15 were taken individually in three concentrations of $3 \%, 4 \%$, and $5 \% \mathrm{w} / \mathrm{w}$. Batch containing $3 \% \mathrm{w} / \mathrm{w}$ HPMC 15 produced thin and plastic like film. Batch containing 3\% w/w Pullulan showed very fast disintegration time and drug release was found to be good. Batch containing 3\% w/w HPMC E5 was found to be sticky. Visual appearances such as transparency offered by these films were also very poor. Batches containing $4 \% \mathrm{w} / \mathrm{w}$ of all the polymers produced soft film and disintegration time and texture was found to be good. Films of $5 \% \mathrm{w} / \mathrm{w}$ of Pullulan had white spots on it and were found to be brittle. $5 \% \mathrm{w} / \mathrm{w}$ of HPMC E5 and HPMC

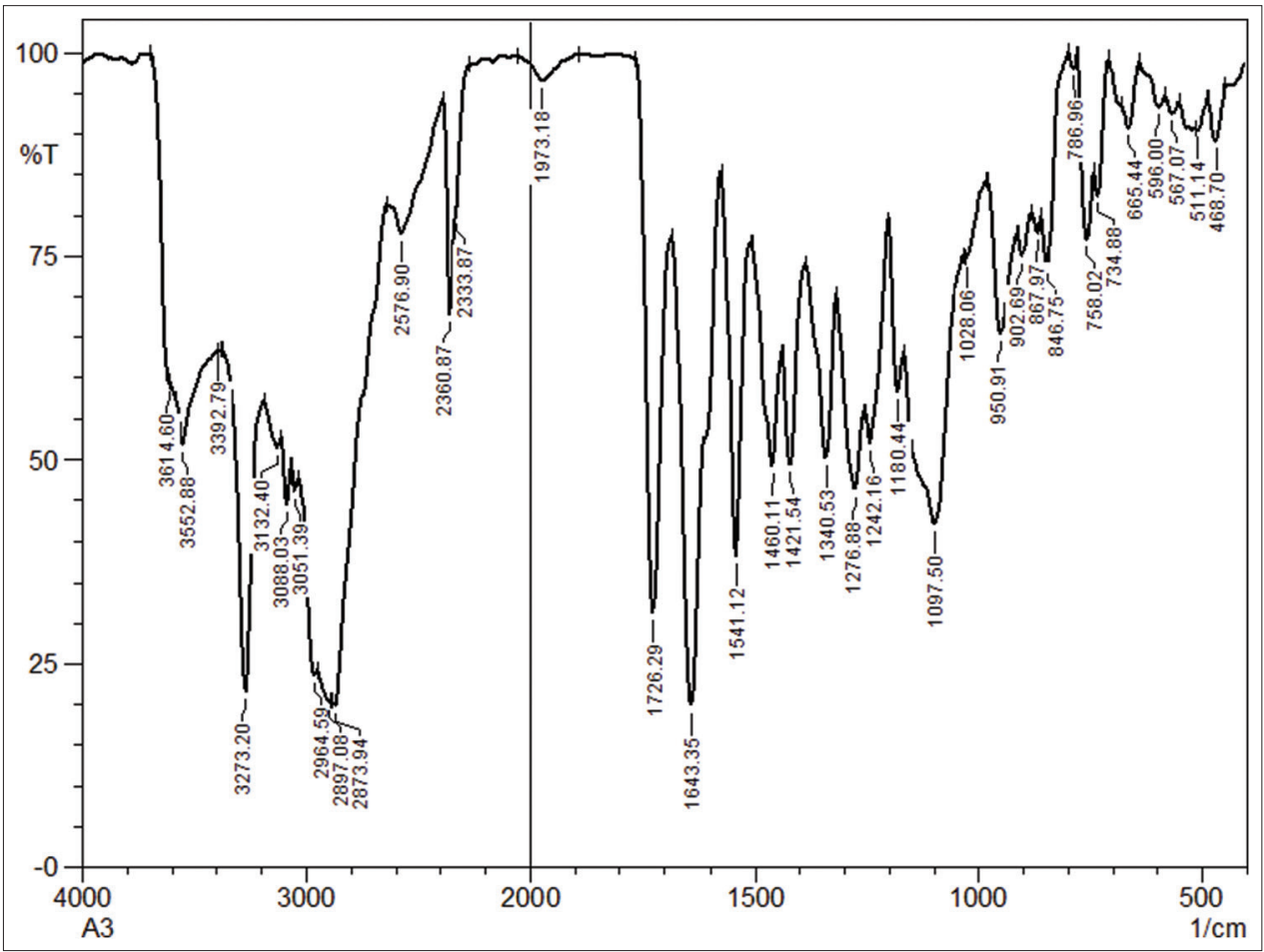

Fig. 1: FTIR Spectrum of RF-Pullulan physical mixture 


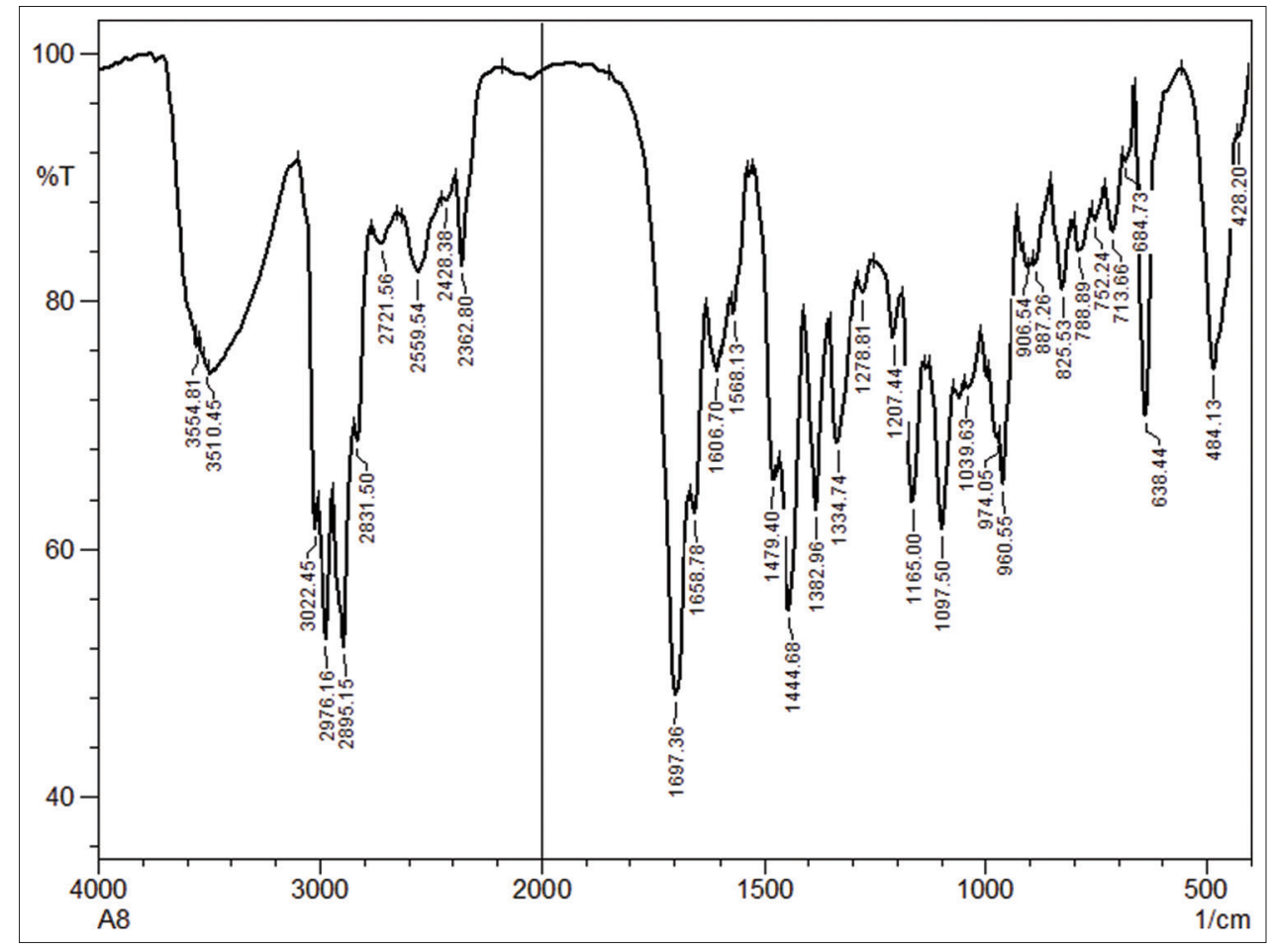

Fig. 2: FTIR Spectrum of RF-HPMC E15 physical mixture

Table 3: Data for standard plot of RF

\begin{tabular}{ll}
\hline Concentration $(\boldsymbol{\mu g} / \mathbf{m l})$ & Absorbance $\overline{\mathbf{x}}^{*} \pm$ SD \\
\hline 0 & 0 \\
10 & $0.1407 \pm 0.016$ \\
20 & $0.3342 \pm 0.011$ \\
30 & $0.4923 \pm 0.013$ \\
40 & $0.6571 \pm 0.012$ \\
50 & $0.8028 \pm 0.009$ \\
\hline
\end{tabular}

E15 had a smooth texture and disintegration was quick. Hence, $3 \%$ and $4 \% \mathrm{w} / \mathrm{w}$ of Pullulan and $4 \%$ and $5 \% \mathrm{w} / \mathrm{w}$ of HPMC E5 and HPMC E15 were selected as the required concentration of polymers. All the trial batches contained PEG 400 as plasticizer. Films prepared with $1 \mathrm{ml}$ of PEG 400 were found to be sticky. Films made up of $1.5 \mathrm{ml}$ of PEG 400 were found to be hazy and folding endurance was less. Films made up of $2 \mathrm{ml}$ of PEG 400 were also found also hazy but the folding endurance was better. Hence, $2 \mathrm{ml}$ of PEG 400 was selected as the ideal amount for plasticizer.

\section{RF-BCD inclusion complex}

RF-BCD was prepared by kneading method and then evaluated. It was found that the drug content of complex was $90.27 \pm 1.24 \%$ and the saturation solubility was $0.2492 \pm 0.027 \mathrm{mg} / \mathrm{ml}$. The saturation solubility of pure drug is $0.00544 \mathrm{mg} / \mathrm{ml}$. Solubility enhancement of $\mathrm{RF}$ is almost 40 -fold by formulating it into its inclusion complex. Dissolution study showed that the complex gave $85 \%$ release in 5 $\min$ and $93 \%$ in $60 \mathrm{~min}$. Thus, it is suitable for incorporation into OFDF.

\section{Evaluation of OFDF of RF}

The OFDF of RF could be prepared by solvent casting method. RF was incorporated as it BCD inclusion complex. The films obtained were evaluated and the information is given Table 4.

\section{Weight uniformity}

The average weight of the films was calculated for formulation F1-F6 and it varied in the range of $55.8 \pm 0.608 \mathrm{mg}$ to $64.61 \pm 0.83 \mathrm{mg}$ and low standard deviations indicate uniformity of weight between the films.
Table 4: Evaluation of RF OFDF

\begin{tabular}{|c|c|c|c|c|c|c|}
\hline \multirow{2}{*}{$\begin{array}{l}\text { Evaluation } \\
\text { Parameters }\end{array}$} & \multicolumn{6}{|c|}{ Formulations } \\
\hline & F1 & F2 & F3 & F4 & F5 & F6 \\
\hline Weight & 55.8 & 61.2 & 59.8 & 64.61 & 62.8 & 61.0 \\
\hline $\begin{array}{l}\text { Uniformity } \\
\text { (mg) } \bar{x}^{*} \pm S D\end{array}$ & \pm 0.60 & \pm 0.6 & \pm 0.26 & \pm 0.83 & \pm 2.07 & +196 \\
\hline Folding & 83.6 & 78.3 & 117 & 91 & 79.6 & 77 \\
\hline $\begin{array}{l}\text { Endurance } \\
\overline{\mathrm{X}}^{*} \pm \mathrm{SD}\end{array}$ & \pm 3.05 & \pm 1.15 & \pm 3.05 & \pm 2.0 & \pm 1.52 & \pm 3.60 \\
\hline Thickness (mm) & 0.25 & 0.24 & 0.33 & 0.31 & 0.30 & 0.34 \\
\hline$\overline{\mathrm{x}}^{*} \pm \mathrm{SD}$ & \pm & & & \pm 0.05 & 03 & 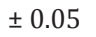 \\
\hline$\% \mathrm{M}_{\mathrm{C}}$ & 1.78 & 1.95 & 1.74 & 1.29 & 2.16 & 1.87 \\
\hline $\begin{array}{l}\text { Absorption } \\
\overline{\mathrm{x}}^{*} \pm S D\end{array}$ & \pm 0.54 & \pm 0.34 & \pm 0.12 & \pm 0.03 & \pm 0.01 & \pm 0.25 \\
\hline$\%$ Moisture loss & 1.68 & 2.12 & 1.95 & 2.46 & 1.7 & 2.95 \\
\hline$\overline{\mathrm{X}}^{*} \pm \mathrm{SI}$ & \pm 0.36 & \pm 0.32 & \pm 0.58 & \pm 0.32 & \pm 1.06 & \pm 1.11 \\
\hline Surface $\mathrm{pH}$ & 6.55 & $6.57 \pm$ & $6.62 \pm$ & 6.59 & $6.72 \pm$ & $6.54 \pm$ \\
\hline$\overline{\mathrm{x}}^{*} \pm S$ & \pm 0.175 & 0.1 & 0 & \pm 0.12 & 0.0 & 0.09 \\
\hline$\%$ Drug Content & 88.18 & 83.73 & 90.88 & 89.11 & $86.23 \pm$ & $84.27 \pm$ \\
\hline$\overline{\mathrm{x}}^{*} \pm \mathrm{SD}$ & \pm 1.45 & \pm 1.25 & \pm 2.07 & \pm 1.92 & 2.57 & 1.65 \\
\hline Disintegration & 31.71 & 30.3 & 28.78 & 36.99 & 37.17 & 36.79 \\
\hline Time (s) & \pm 1.35 & \pm 0.86 & \pm 1.36 & \pm 0.75 & \pm 3.13 & \pm 0.90 \\
\hline$\overline{\mathrm{x}}^{*} \pm \mathrm{SD}$ & & & & & & \\
\hline$(\%)$ & $1.92 \pm$ & 2.2 & 2.4 & 1.89 & 2.63 & 1.80 \\
\hline$\overline{\mathrm{x}}^{*} \pm \mathrm{SD}$ & 0.82 & \pm 0.57 & \pm 0.51 & \pm 0.78 & \pm 0.33 & \pm 0.69 \\
\hline
\end{tabular}

As per the \% weight of the polymer incorporated, the film weight varied accordingly Pullulan film F1 being lowest in weight. F6 with high molecular weight HPMC showed a slight reduction in weight due to higher viscosity and yield issue.

\section{Folding endurance}

The folding endurance measures the ability of the film to withstand rupture for formulation F1-F6 and ranged from $77 \pm 3.60$ to $117 \pm 3.05$. These values indicate fair folding endurance of the film. Folding endurance of F3 and F4 having HPMC E5 was found to be better over that of pullulan and HPMC E15. 


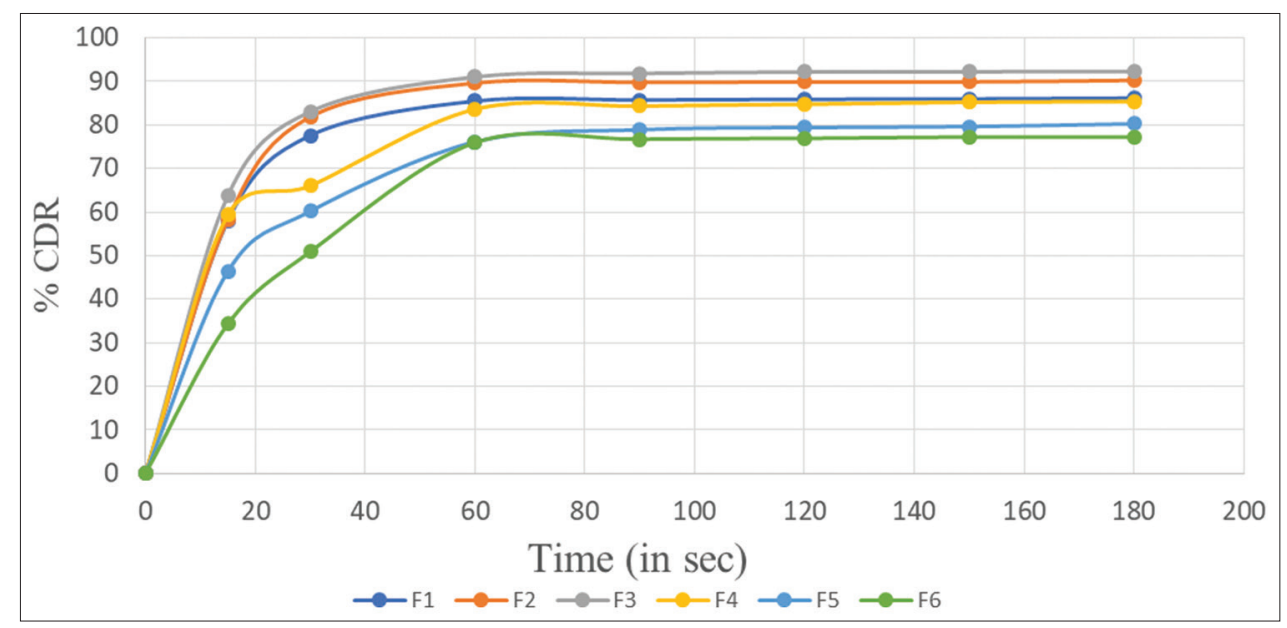

Fig. 3: In vitro drug release profile of RF OFDF

\section{Uniformity of film thickness}

The thickness of the formulated films was found by screw gauge and values for formulation F1-F6 ranged from $0.24 \pm 0.04 \mathrm{~mm}$ to $0.34 \pm 0.05$ $\mathrm{mm}$. The values are almost uniform in all formulations. Formulation F1 and F2, made up of Pullulan were found to be thinner. This is because of the low molecular weight of the polymer. Films made up of HPMC were found to be thicker.

\section{Percentage moisture absorption}

Percentage moisture absorption indicates the stability of the film. The percentage moisture absorption of formulation F1-F6 was found in the range of $1.29 \pm 0.03 \%-2.16 \pm 0.01 \%$. All the formulations except F5 were found to absorb less than $2 \%$ moisture. Since the films take up moisture they have they have to be protected from such environment.

\section{Percentage moisture loss}

Percentage moisture loss indicates the integrity of the films at dry conditions. The percentage moisture loss of formulations F1-F6 was found in the range of $1.68 \pm 0.36 \%$ to $2.95 \pm 1.11 \%$. F 4 and F6 had higher moisture loss and it was seen that the films were found to lose flexibility.

\section{Surface pH study}

The $\mathrm{pH}$ of the formulations F1-F6 ranged from $6.54 \pm 0.09$ to $6.72 \pm$ 0.098 . The $\mathrm{pH}$ of the formulations was close to the salivary $\mathrm{pH}$.

\section{Drug content uniformity}

The drug content was performed to ensure that the films had uniform and accurate distribution of the drug. Amount of drug present for formulation $\mathrm{F} 1-\mathrm{F} 6$ ranged from $83.73 \pm 1.25 \%$ to $90.88 \pm 2.07 \%$ which is within the limit of $85-115 \%$, apart from formulation F2. It may be concluded that variation of drug content is due to slightly high standard deviation in the RF inclusion complex.

\section{Disintegration time}

Disintegration time is the time when the film starts to break. The duration of the films to disintegrate in water for the formulations F1-F6 ranged from $28.78 \pm 1.36 \mathrm{~s}$ to $37.17 \pm 3.13 \mathrm{~s}$. All were found to disintegrate within 1 min. F5 and F6 with HPMC 15cps were found to disintegrate slowly possibly because of the relatively higher viscosity grade.

\section{Percentage elongation}

Percentage elongation value gives us the idea of the mechanical strength of the film. Percentage elongation of the formulations F1-F6 ranged from $1.80 \pm 0.69 \%$ to $2.63 \pm 0.33 \%$.

\section{In vitro drug release profile}

The cumulative drug release was calculated on the basis of drug content of oral films. The results are presented in Fig. 3. The results varied based on type and proportion of polymers. Formulation F1 and F2 containing
Table 5: Stability study of F3 at $40 \pm 2^{\circ} \mathrm{C}$ and $75 \pm 5 \% \mathrm{RH}$

\begin{tabular}{llll}
\hline Evaluation Parameters & At 0 days & At 30 days & At 60 days \\
\hline Drug content & $90.88 \%$ & $89.82 \%$ & $89.36 \%$ \\
Disintegration time & $29 \mathrm{~s}$ & $29 \mathrm{~s}$ & $30 \mathrm{~s}$ \\
\%Drug release & $92.11 \%$ & $91.98 \%$ & $90.23 \%$ \\
\hline
\end{tabular}

Pullulan showed release of $86.15 \pm 0.337 \%$ and $90.24 \pm 0.302 \%$ for 180s. Formulation F3 and F4 containing HPMC E5 showed release of $92.32 \pm 0.275 \%$ and $85.41 \pm 0.267 \%$ for 180 s. Formulation F5 and F6 containing HPMC E15 showed release of $80.26 \pm 0.38 \%$ and $77.24 \pm 0.173 \%$ for $180 \mathrm{~s}$. Formulation containing Pullalan $400 \mathrm{mg}$ (F2) showed good release pattern. Formulation containing HPMC E5 $400 \mathrm{mg}$ (F3) showed good release of the drug with good folding endurance, disintegration time, and drug content. Thus, formulation F3 was selected as the most satisfactory formulation.

\section{Stability study}

Selected formulation F2 after 2 months of stability study when stored at $40 \pm 2^{\circ} \mathrm{C}$ and $75 \pm 5 \% \mathrm{RH}$, showed not much change in evaluation parameters of the compared to the initial values. The data are given in Table 5 .

\section{CONCLUSION}

In the present study, an attempt was made to develop OFDF containing $\mathrm{RF}$ for allergic rhinitis. RF is water insoluble drug. OFDF of RF could successfully be prepared by incorporating the drug as its inclusion complex with beta-cyclodextrin. Pullulan and HPMC E5 and E 15 as film forming materials were suitable to prepare OFDF. Based on in vitro drug release, disintegration time, folding endurance, and drug content F3 OFDF containing HPMC E 5 showed better properties and was selected as the as the best formulation. Stability study for 2 months showed no significant change in physicochemical properties, drug contents and in vitro dissolution pattern of F3. Thus, stable OFDF of RF could successfully be formulated which may be suitable for treatment of allergic rhinitis.

\section{ACKNOWLEDGMENTS}

The authors are grateful to Hetero Labs, Hyderabad, for providing a gift sample of the drug. The authors thank the principal and management, Acharya and BM Reddy College of Pharmacy, Bengaluru, for providing the necessary facilities to carry out this work.

\section{AUTHOR'S CONTRIBUTION}

The work was conceived and executed by Mr. Abhibrata Roy. Supervision of the experimental work and manuscript preparation was done by Dr. Madhavi. Manuscript work was assisted by Mr. Reegan. 


\section{CONFLICTS OF INTEREST}

The authors declare that they have no conflicts of interest in this study.

\section{AUTHORS FUNDING}

The work has been funded by the management, Acharya and BM Reddy College of Pharmacy, Bengaluru.

*This work has been presented in part at National Seminar on Recent Advances in Dosage Form Design and Their Impact on Clinical Pharmacy, University College of Pharmaceutical Sciences, Andhra University, Visakhapatnam, July 14, 2018.

\section{REFERENCES}

1. Small P, Harold K. Allergic rhinitis. Allergy Asthma Clin Immunol 2011;7:34-41

2. Wheatley LM, Togias A. Allergic rhinitis. N Engl J Med 2015;372:456-63.

3. Mirmoezzi MS, Yazdi MS, Gholami O. Comparative study on the efficacy of mometasone and fluticasone nasal sprays for treatment of allergic rhinitis. Int J Pharm Pharm Sci 2017;9:211-4.

4. Mittal PA, Godse KV, Patil SP. Second-generation antihistamines. Ind J Drug Derm 2016;2:3-12.

5. Vondark B, Bamhart S. Dissolvable films for flexible product format in drug delivery. PharmTech 2008;1:41-5.

6. Frey P. Film Strips and Pharmaceuticals. Pharmaceutical Manufacturing and Packaging Source Winter; 2006. p. 92-3.

7. Zhang H, Zhang J, Streis JB. Oral mucosal drug delivery: Clinical pharmacokinetics and therapeutic applications. Clin Pharmacokinet 2002;41:661-80.

8. Krishnaveni J, Ali MS, Vijender C, Sudheer KD. Formulation and evaluation of fast dissolving oral films of diazepam. J Pharmacovigil 2016;4:1-5.

9. Senthilkumar K, Vijaya K. Formulation development of mouth dissolving film of etoricoxib for pain management. Adv Pharm
2015;2015:702963.

10. Kathapali H, Patil A. Formulation and evaluation of orally disintegrating films of levocetirizine dihydrochloride. Ind J Pharm Sci 2017;79:204-11.

11. Chaudhury H, Gauri S, Rathee P, Kumar V. Development and optimization of fast dissolving oro-dispersible films of granisetron HCL using box-behnken statistical design. Bull Fac Pharm Cairo Univ 2013;51:193-201.

12. Castillo H, Vargas ZR, Carazo BG, Madrigal RG, Calvo GB, Baltodano VE. Development of immediate release rupatadine fumarate $10 \mathrm{mg}$ tablets: A quality by design (QbD) approach. Drug Dev Ind Pharm 2019;45:1674-81.

13. Wasilewska K, Szekalska M, Ciosek-Skibinska P, Lenik J, Basa A, Jacyna J, et al. Ethylcellulose in organic solution or aqueous dispersion form in designing taste-masked microparticles by the spray drying technique with a model bitter drug: Rupatadine fumarate. Polymers 2019; $11: 522$

14. Ferrer MM, Capdevila MS. Liquid Formulations of Rupatadine Fumarate. European Patent Office, No. EP2402012B1; 2012.

15. Raj RA, Nair SS, Harindran J. Formulation and evaluation of cyclodextrin inclusion complex tablets of carvedilol. Asian J Pharm 2016;10:84-94

16. Yassin GE, Abass HA. Design and evaluation of fast dissolving oro-dispersible films of metoclopramide hydrochloride using 32 multifactorial designs. Int J Pharm Pharm Sci 2016;8:218-22.

17. Sri KV, Ravishanker D, Rohini P, Subbarao M. Formulation and in vitro evaluation of sumatriptan succinate oral thin films. Ind Am J Pharm Res 2013;3:3016-25

18. Kumar KR, Sulochona MM. Fast dissolving films a unique strategy for drug delivery. Asian J Pharm Res 2014;4:47-55

19. Kumar SR. An update on fast dissolving films. World J Pharm Pharm Sci 2014;5:466-86.

20. Chauhan NS, Tomar A, Sharma K, Mittal A, Bajaj U. Formulation and evaluation of fast dissolving oral film of dicyclomine as potential route of buccal delivery. Int J Drug Dev Res 2012;4:408-17.

21. Bais PV, Upadhye KP, Dixit G. Formulation and evaluation of fast dissolving oral melt-in-mouth of lorazepam for sublingual use. World J Pharm Pharm Sci 2016;5:763-75. 